Vergara Erices, Luis Alejandro. El estado subsidiario y sus políticas urbanas: la expulsión de los estratos bajos de la ciudad. GeoGraphos. [En línea]. Alicante: Grupo Interdisciplinario de Estudios Críticos y de América Latina (GIECRYAL) de la Universidad de Alicante, 6 de febrero de 2014, vol. 5, no 62, p. 146166 [ISSN: 2173-1276]. [DOI: 10.14198/GEOGRA2014.5.62].

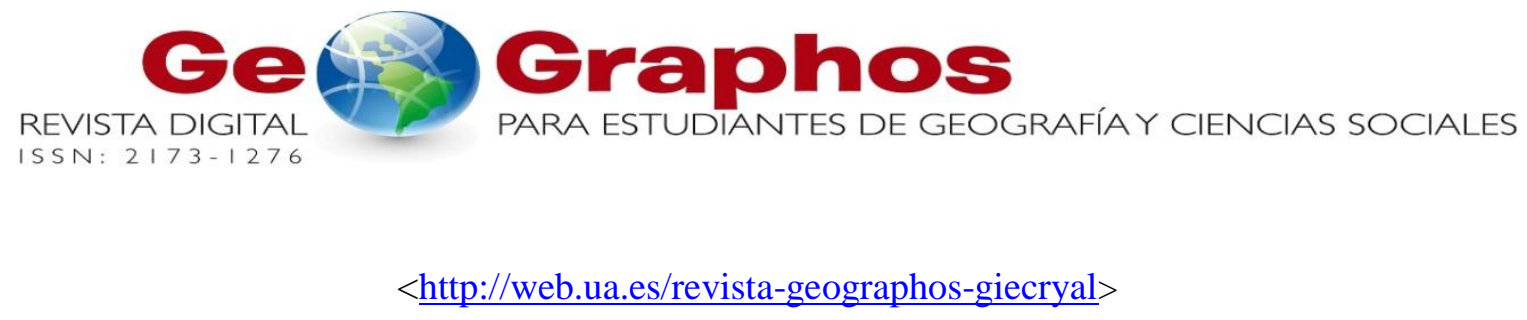

Vol. 5. $\mathrm{N}^{\mathrm{o}} 62$

Año 2014

\title{
EL ESTADO SUBSIDIARIO Y SUS POLÍTICAS URBANAS: LA EXPULSIÓN DE LOS ESTRATOS BAJOS DE LA CIUDAD
}

\author{
Luis Alejandro Vergara Erices \\ Estudiante de Magister en Ciencias Sociales Aplicadas \\ Universidad de La Frontera (Temuco, Chile) \\ Correo electrónico: 1.vergara002@gmail.com
}

Recibido: 10 de agosto de 2013. Aceptado: 6 de febrero de 2014

\section{RESUMEN}

En los setenta la economía mundial experimentó una fuerte crisis, gatillada según economistas neoliberales, por la magnificencia que había adquirido el estado durante la fase capitalista anterior, por lo que la solución involucraba necesariamente reformular el rol del estado, contrayendo su accionar y dejando el espacio abierto para la libre acción del mercado. El estado subsidiario se implementó en Chile durante la dictadura militar y sus modificaciones se hicieron sentir tanto en las estructuras sociales como espaciales. En lo que respecta a la ciudad el estado subsidiario diseñó una nueva política de desarrollo urbano, que entregaba la regulación y la distribución del suelo exclusivamente al mercado y dejaba en manos de la empresa privada el desarrollo de las ciudades nacionales. La especulación inmobiliaria y la creciente necesidad por suelo urbano generaron un alza constante de su precio. Ante este panorama las clases bajas comienzan lentamente a ser expulsadas de la ciudad ya que no pueden pagar por si solas una vivienda bien ubicada dentro de la mancha urbana. El mecanismo con el cual se expulsa el estrato bajo de la ciudad es la vivienda social, que también se ve reformulada en base a los preceptos neoliberales durante los setenta. 
Palabras clave: Estado subsidiario, vivienda social, política de desarrollo urbano, pobreza urbana.

\title{
THE SUBSIDIARY STATE AND HIS URBAN POLITICS: THE EXPULSION OF THE LOW STRATA OF THE CITY
}

\begin{abstract}
In the seventies the world economy experienced a crisis, triggered by the magnificence neoliberal economists that the state had acquired during the previous capitalist, so that the solution necessarily involved reformulating the role of the state, contracting their actions and leaving open space to the free market action. Subsidiary status was implemented in Chile during the military dictatorship and its modifications were felt both in social and spatial structures. With respect to the city subsidizing state designed a new urban development policy, regulation and delivering soil distribution exclusively to market and left it to private enterprise to develop domestic cities. Real estate speculation and the growing need for urban land generated a steady rise in its price. Against this background the lower classes slowly begin to be expelled from the city because they can not pay for themselves a home well located within the urban area. The mechanism by which ejects the lower stratum of the city's social housing, which is also reformulated based on neoliberal precepts during the seventies.
\end{abstract}

Key Words: Subsidiary Status, Social housing, Urban Development Policy, Urban Poverty.

\section{ESTADO SUBSIDIÁRIO E URBANO POLÍTICAS: A EXPULSÃO DO ESTRATOS BAIXOS DA CIDADE}

\section{RESUMO}

Nos anos setenta a economia mundial sofreu uma crise, desencadeada segundo economistas neoliberais pela magnificência que o Estado tinha adquirido durante fase capitalista anterior, de modo que a solução necessariamente envolver a reformulação do papel do Estado, a contratação de suas ações e deixando espaço aberto para a ação do livre mercado. Estado subsidiário foi implantado no Chile durante a ditadura militar e suas modificações foram sentidas tanto nas estruturas sociais e espaciais. Em relação à cidade do estado subsidiário projetou uma nova política de desenvolvimento urbano, a regulação e distribuição dos solos entregar exclusivamente ao mercado e deixou-o à iniciativa privada para desenvolver cidades nacionais. A especulação imobiliária ea crescente necessidade de terra urbana gerou um aumento constante em seu preço. Neste contexto, as classes mais baixas começam lentamente a ser expulso da cidade porque não podem pagar por eles próprios uma casa bem localizada dentro da área urbana. $\mathrm{O}$ mecanismo pelo qual ejecta o estrato inferior da habitação social da cidade, o que também é reformulada com base em preceitos neoliberais durante os anos setenta.

Palavras chave: Estado subsidiario, moradia social, política de desenvolvimento urbano, pobreza urbana. 


\section{INTRODUCCIÓN}

Actualmente un $87 \%$ de la población chilena habita en alguna ciudad (INE, 2012), por lo tanto nuestro país se constituye como una nación esencialmente urbana. Sin embargo, realizando una lectura histórica se evidencia que esta sociedad urbana es relativamente reciente ya que hace tan sólo cinco décadas la población que habitaba en las zonas rurales superaba ampliamente a la población que vivía en la ciudad. Si bien es cierto que el ritmo de crecimiento de las zonas urbanas en estas últimas décadas ha disminuido e incluso se han evidenciado ciertos procesos de contra urbanización, la población que vive en ciudades continúa en aumento tanto en términos absolutos como también en términos relativos.

Ante el panorama expuesto, la ciudad se establece como el espacio por excelencia donde las personas desarrollan sus vidas, trabajan, estudian, se enferman, forman familia y también sociabilizan. En efecto según H. Capel (2003) uno de los elementos indispensables que conforman una ciudad es la diversidad de clases sociales que coexisten en ella: clase alta, baja, media, todas relacionándose entre sí y conformando socialmente la ciudad.

El proceso de migración campo-ciudad, que comenzó a experimentar Chile durante el siglo anterior y específicamente en la década del cincuenta, marcó el inicio de un país urbano. Este fenómeno de migración rural-urbana estuvo fundamentalmente centrado en la movilidad espacial de una sola clase social; la clase baja, que veía como lentamente su actividad laboral principal, la agricultura, perdía terreno e importancia frente a la incipiente actividad industrial que se desarrollaba en las ciudades y la que les ofrecía una "supuesta" mejor calidad de vida.

La movilización de grandes contingentes de población obrera a la ciudad industrial gatilló un crecimiento explosivo de la población que habitaba en lo urbano, sobrepasando y desboronando así todos los límites y criterios impuestos por la escasa planificación territorial de la época. Como la ciudad no estaba preparada para recibir tan grande contingente poblacional los nuevos habitantes se veían obligados a vivir como allegados o incluso tomarse terrenos privados, por lo que el estado, por aquella época benefactor, comenzó a diseñar una serie de políticas públicas que enfrentaban este problema y trataban de disminuir el déficit habitacional de la época bajo una perspectiva global, es decir a través de una vivienda económica ubicada en un barrio que contenía escuelas, campos deportivos, centros asistenciales y una serie de otros servicios básicos.

Sin embargo, el panorama de los pobres en la ciudad comienza a cambiar drásticamente en la década del setenta y es que con la llegada de la dictadura el estado reformuló su actuar en materia de vivienda social y en materia de desarrollo urbano. El estado subsidiario comenzó a desplegar sobre el territorio nacional políticas públicas que tuvieron como consecuencia, deseada o indeseada, la expulsión de la pobreza urbana de los buenos lugares de la ciudad, e incluso de la misma ciudad hacia los espacios rururbanos. Esta expulsión de los estratos bajos de la ciudad es un fenómeno que puede ser apreciado en diversas ciudades nacionales, principalmente en las grandes áreas metropolitanas (Santiago, Valparaíso y Concepción) y en algunas capitales regionales (por ejemplo Temuco, Puerto Montt, Iquique).

Este artículo busca reflexionar sobre el rol del estado, en su lógica neoliberal, en la movilidad espacial que han tenido los estratos bajos en las ciudades nacionales. Se 
plantea como hipótesis que el estado a través de las políticas urbanas y de vivienda social desplegadas en las últimas cuatro décadas ha tendido a expulsar a los estratos bajos de la ciudad, segregándolos en ciertos espacios del límite urbano o incluso expulsándolos fuera de la ciudad a través de la creación de la precariopolis estatal. Estas fuerzas centrifugas que han expulsado la pobreza de la ciudad han sido generadas esencialmente por los cambios paradigmáticos que el estado chileno experimentó en la década del setenta y que se ven reflejados en los principios que guían el desarrollo urbano nacional y la política de vivienda social, principal fuente de obtención de vivienda por parte de la clase baja.

Para argumentar la hipótesis planteada, este trabajo se estructura de la siguiente manera, en primer lugar revisaremos los cambios experimentados por el estado en la década del setenta y que transforman al estado benefactor garante del desarrollo nacional en un estado subsidiario que delega su responsabilidad a la iniciativa privada, situación que se ve reflejada en la nueva política urbana de 1979 y en la nueva lógica sobre la cual se funda la política de vivienda social. Con aquel constructo teórico analizaremos finalmente la movilidad espacial de los estratos bajos en la ciudad chilena neoliberal (1979-actualidad) a través del estudio de la localización de la vivienda social.

\section{LA REESTRUCTURACIÓN ESTATAL Y SU REFLEJO EN LA CIUDAD}

La década del setenta y específicamente el año 1973, se constituye como un punto de inflexión en la historia del capitalismo (crisis del petróleo) y también en la historia de nuestro país (Golpe de Estado). Los setenta estuvieron antecedidos por cuatro décadas de expansión capitalista mundial (Huerta, 2005), impulsada bajo la lógica del estado benefactor o también llamado keynesiano, sin embargo mientras el capitalismo industrial se expandía, internamente se fueron generando algunas contradicciones, que vinieron a salir a la luz en los sesenta, por ejemplo la crisis de sobre producción Europea y Japonesa, y paralelamente la crisis de los modelos de industrialización en América Latina (Harvey, 1998), estas situaciones desembocaron en la crisis internacional del petróleo en 1973, situación que no pudo ser resuelta por la acción centralizada del estado.

Ante el contexto de crisis económica el debate respecto a las posibles soluciones se intensificó, preponderando ante cualquier otra postura la de los economistas neoliberales $^{1}$, representados por Friedman, Hayek y Popper (Vargas, 2000). Estos economistas planteaban que la crisis capitalista había sido gatillada justamente por el gran tamaño y el deficiente funcionamiento del estado en la regulación de la economía y la asignación de los bienes y servicios públicos (Huerta, 2005)

Por lo tanto la solución a la crisis económica global pasaba necesariamente por reformular el rol que había asumido el estado regulador de la economía, ya que el involucramiento estatal impedía que el sistema económico fuera eficiente, era mejor entonces la desregulación económica. Por consiguiente se opta por modificar el rol que

\footnotetext{
${ }^{1}$ Entre los factores que influyen en el triunfo de las posturas neoliberales se encuentra la reacción extremadamente conservadora de los países "desarrollados" frente a la crisis, la aparición de nuevas elite tecnocráticas inspiradas en los ideales neoliberales, la caída de las teorías dependentistas, entre otras (Chonchol, 1996).
} 
tenía hasta ese momento el estado el que comienza a reestructurarse con el fin de garantizar la continuidad del capitalismo mundial.

Desde el setenta en adelante el rol del estado se comienza a limitar exclusivamente a la creación de un clima acogedor para el desarrollo de los negocios y la libre circulación mundial del capital (Harvey, 1998).

Producto de la crisis capitalista mundial el estado experimenta una profunda reestructuración tanto en sus funciones como en su tamaño (De Mattos, 1992), aquel estado que brindaba servicios sociales gratuitos (educación, salud, vivienda, etc.), que administraba empresas, que regulaba la macroeconomía, comienza una vertiginosa retirada y es el mercado quien asume las funciones por este antes realizadas, por ello entre otras cosas, se comienza a confeccionar un plan de privatizaciones de empresas públicas, la privatización de la educación y salud, etc. El estado ahora asume un rol subsidiario y abandona su función benefactora.

Nuestro país, por supuesto, no estuvo ajeno a esta reestructuración estatal -Chile es el primer país en asumir este modelo- y es que en la década del setenta, en un contexto de dictadura militar, se implementaron una serie de profundas y paradigmáticas reformas refundacionales del estado. La junta militar, liderada por Augusto Pinochet, argumentando una profunda crisis económica, social y política en Chile consideró que era necesario realizar una reforma sustantiva al sistema de desarrollo nacional con el fin de construir así un nuevo orden que diera solución a la crisis que experimentaba nuestro país. Esta reforma estuvo enteramente asesorada por los llamados Chicago boys, profesionales egresados de la Universidad de Chicago (EE.UU.), cuyas ideas respondían plenamente a los acuerdos asumidos por nuestro país con el Fondo monetario internacional durante la década del setenta quien promovía la contracción estatal y la ampliación del mercado. Los Chicago boys instauraron en Chile un modelo de economía de libre mercado basado en la desregulación de la economía a partir de la progresiva eliminación del papel arbitral del estado (Garretón, 1982). Surge así la figura del estado neoliberal que abandona el papel promotor del desarrollo a cambio de que su antigua posición sea ocupada plenamente por el mercado.

Así la dictadura militar comenzó a mediados de los setenta, a desarrollar una serie de reformas que hicieron que Chile abrazara las doctrinas neoliberales y abriera sus puertas al mercado mundial y al proceso de Globalización. (Borsdorf, Sánchez y Marchant, 2008). Estas medidas comenzaron a generar una serie de transformaciones que se hicieron sentir fuertemente sobre las estructuras sociales y espaciales de nuestro país y que respondían plenamente a la lógica neoliberal y a la reestructuración estatal. A continuación revisaremos dos de las políticas confeccionadas desde estado subsidiario, que responden plenamente al proceso de contracción del estado y ampliación del mercado -la política de desarrollo urbano y la política de vivienda social- y que se constituyen como esenciales para analizar la movilidad de los estratos bajos en la ciudad chilena de las últimas décadas.

\section{El neoliberalismo llega a la ciudad: La política de desarrollo urbano de 1979}

¿Cómo es que los principios neoliberales del nuevo estado se plasman dentro de la ciudad? Para darle respuesta a esta interrogante es necesario revisar la política de 
desarrollo urbano de 1979, que posteriormente sufre leves modificaciones en 1985, y que sustenta las bases que rigen hasta hoy la dinámica de las ciudades chilenas.

La ciudad en este nuevo contexto capitalista se ha vuelto el centro de la circulación del capital, se ha convertido en un punto estratégico del comercio mundial. Como bien lo documentan S. Sassen (1991) y J. Friedmann (1986), hoy las ciudades son globales ya que están conectadas con el resto del mundo a través de intensas redes comerciales y tecnológicas.

Para que la ciudad se acoplara de manera exitosa a esta nueva dinámica neoliberal y globalizante el estado chileno diseñó una política que regula su crecimiento, los usos del suelo y la distribución de este a través de criterios impuestos por las leyes del mercado, provocando así una disminución la injerencia del aparato estatal en la coordinación del desarrollo urbano nacional.

Entre las modificaciones propuestas por esta política encontramos primero que el recurso suelo en las ciudades chilenas deja de ser considerado como un bien escaso, segundo la eliminación de las normas referidas al límite urbano y también algunos impuestos y regulaciones estatales al mercado urbano, tercero se liquida el suelo urbano que estaba en manos del estado y se le entrega a empresas privadas y cuarto se consideró que era el mercado quien debía regular y asignar los usos y la distribución del suelo urbano a través de la libre competencia (Sabatini, 2000; Garín, Salvo y Bravo, 2009; Montes, 1999). En síntesis esta nueva política de desarrollo urbano consideró que era necesaria la liberalización del mercado de tierras convirtiendo al suelo urbano en un bien libre cuya transacción debía estar regulada solamente por las fuerzas del mercado; la oferta y la demanda, modificando así de manera severa la antigua política de desarrollo urbano que promovía el gobierno Socialista de Salvador Allende donde la vivienda y la tierra era un bien al cual todos tenían derecho a acceder y su distribución estaba determinada por las necesidades y condiciones sociales (Hidalgo, 2007; Palma y Sanfuentes, 1979).

Según C. Montes (1999), la nueva política de desarrollo urbano planteada por el gobierno militar tenía cuatro objetivos principales, a saber: el primero de ellos era la conformación de un sector inmobiliario privado que pudiera hacerse cargo del desarrollo urbano nacional, remplazando así la antigua labor que estaba en manos del estado. Segundo, que el desarrollo urbano se rigiera por criterios de rentabilidad generados a partir de la propia dinámica del mercado, en este sentido se consideraba que al eliminar la norma referida al límite urbano se igualarían los precios de la tierra urbana con la tierra rural. Tercero, al liberar los usos de suelo por las trabas ofrecidas por las normas planificación urbana los precios de los suelos comenzarían a experimentar una tendencia a la baja. Finalmente, en cuarto lugar, se pensaba que a la larga esta política permitiría a los grupos sociales bajos acceder a la compra de viviendas contribuyendo de esta forma al mejoramiento en la calidad de vida de la población.

Según el autor anterior, quien hace una evaluación de los impactos de la política de desarrollo urbano en Chile, los dos primeros objetivos se lograron, sin embargo los últimos dos no lo han hecho, por el contrario esta nueva política ha contribuido a un aumento en el precio del suelo urbano (Hidalgo, 2007; Sabatini, 2000) y un aumento de la segregación residencial de las ciudades (Garín, Salvo y Bravo, 2009; Sabatini, 2000; Azocar et al, 2008). 
Con la política de desarrollo urbano se liberaliza el suelo, el estado ya no es quien debe planificar la ciudad, sino que debe ser el mismo mercado a través de la oferta y la demanda lo que va a regular el uso del suelo y la distribución de este, el desarrollo urbano por consiguiente queda en manos de las constructoras y empresas inmobiliarias, el suelo se ajusta así completamente a la nueva lógica de contracción estatal y los mejores lugares de la ciudad quedan resguardados solamente para quienes pueda pagar por ellos.

\section{La nueva lógica de la vivienda social}

Ahora bien, cabe preguntarse también qué sucedió con la necesidad de vivienda que experimentaban los habitantes pobres de las ciudades nacionales que aún se encontraban sin casa o sin un terreno para construirla. Pues bien, para darle solución a este problema el estado, ya reestructurado, rediseñó la política de vivienda social.

La política de vivienda social, principal motor de vivienda de las clases bajas en nuestro país, también vio reestructura sus bases y principios en la década del setenta. Según R. Hidalgo (2005), la vivienda social, que es asumida en este trabajo como aquella residencia que es entrega a los estratos sociales bajos por medio de una acción coordinada desde el estado (Hidalgo, 2005; Haramoto, 1987), con las reformas impuestas de los setenta, deja de ser una responsabilidad netamente del estado, al respecto el Ministerio de Vivienda y Urbanismo (en adelante MINVU) señala lo siguiente: "la política habitacional del supremo gobierno establece que la vivienda es un derecho que se establece con esfuerzo y ahorro, acción en la cual la familia y el estado comparten su cuota de responsabilidad. La vivienda no es por lo tanto un regalo del estado" (MINVU, 1976, p. 2). Así ahora la vivienda social debe ser necesariamente un producto de responsabilidad compartida, entre el estado y la familia, terminando por tanto con el rol benefactor del estado en materia de vivienda.

Según M. Castillo y R. Hidalgo (2005), la situación en materia de vivienda en la década del setenta era crítica ya que existían una gran cantidad de asentamientos precarios derivados de la llamada "operación sitio", las tomas de terreno y un gran número de campamentos. Así el gran desafío a enfrentar en materia de vivienda eran los altos niveles de déficit habitacional que presentaba Chile y regularizar la condición en que se encontraban las familias que habitaban en los distintos asentamientos precarios. Para enfrentar estos problemas la dictadura militar en base a la política de desarrollo neoliberal, elaboró en 1978 el sistema de subsidio habitacional, sistema basado en una bonificación que era entregada por el estado en relación al valor de la vivienda que quería comprar una familia, la que previamente debía haber ahorrado una cierta cantidad de dinero.

Ahora bien, si el ahorro individual más lo aportado por el estado a través de la bonificación no alcanzaba para realizar la compra de vivienda, era la familia quien debía recurrir a un tercer actor en la fórmula; las instituciones financieras-Bancos, las que le otorgarían un crédito habitacional (Casgrain, 2010) pudiendo cumplir de esta forma, las familias, el anhelado sueño de la casa propia. Este mecanismo, que es más bien un subsidio a la oferta y no a la demanda como señalada la literatura ya que "el valor efectivo es pagado a la empresa que construye la casa" del beneficiario y no al beneficiario propiamente tal quien es el que demanda la casa (Sugranyes, 2005, p. 27), 
está basado en tres pilares fundamentales; el ahorro, el subsidio y el crédito, aquella es la fórmula mágica propuesta por los Chicago boys para disminuir los altos niveles de déficit habitacional que aquejaban a Chile en los ochenta.

Sin embargo también el estado asumió la entrega de la llamada vivienda económica, la que era concedida a aquellas familias de más escasos recursos a través de los programas de vivienda básica, vivienda progresiva, etc.

Así, los mecanismos de financiamiento de la vivienda social que asume el estado en los setenta son dos: el subsidio habitacional para aquellas familias que puedan tener capacidad de ahorro y acceso al crédito para la vivienda y un segundo mecanismo de subsidio es la construcción de viviendas para grupos con muy escaza posibilidad de ahorro y nula posibilidad de crédito. Estos dos mecanismos de financiamiento han estado en la base de la política de vivienda implementada desde el setenta y que en términos cuantitativos ha sido plenamente exitosa, ya que el déficit habitacional detectado en los ochenta ha disminuido considerablemente, de ahí que muchos países latinoamericanos hayan comenzado a imitarla. Sin embargo desde el punto de vista cualitativo esta no lo ha sido tanto considerando los problemas de calidad de vivienda, la baja movilidad social, la delincuencia, la segregación y "guetificación" de ciertas zonas, consecuencias bien documentadas por la literatura especializada.

En esta nueva lógica neoliberal, el facilitador de la política de vivienda social en nuestro país ha sido el estado el que ha asumido una función netamente subsidiaria, en tanto que el ejecutor del modelo son un pequeño grupo de empresarios representados por la cámara chilena de la construcción (CCHC) quienes controlan la intervención, las tipologías y la localización de las viviendas sociales construidas. (Sugranyes, 2005).

Tanto la política de vivienda social como la de desarrollo urbano fueron diseñadas por este nuevo estado, reestructurado, pequeño y que delega muchas de sus antiguas responsabilidades a la empresa privada, el subsidio habitacional es un ejemplo de ello. Estas nuevas políticas han tenido un impacto sobre la movilidad espacial de los estratos bajos los que han tenido que irse a vivir a la periferia urbana o bien fuera de la ciudad producto de la constante alza del precio del suelo urbano, aumento gatillado por la creciente especulación inmobiliaria y el efecto de la propia dinámica del mercado, este incremento no ha podido ser frenado y ha obligado a construir la vivienda social en la periferia de las ciudades.

A continuación pasaremos a revisar la movilidad espacial que ha experimentado la clase baja. Se asume en este trabajo que el principal mecanismo de expulsión de los pobres de la ciudad ha sido la vivienda social, como hemos señalado principal fuente de acceso de la vivienda de los estratos bajos, es por aquello que en la siguiente sección se aborda la movilidad espacial de estos estratos a través del estudio de los patrones de localización que ha adquirido la vivienda social.

Se realizó una división temporal en cuatro etapas con el fin de explicar de mejor manera la movilidad de los estratos bajos hacia la periferia, sin embargo es importante acotar que los límites de este periodo en ningún caso son rígidos, son solo esquemáticos. La primera de ellas va desde 1979 a 1989 y está caracterizada esencialmente por los traslados de los campamentos ubicados en las ciudades nacionales, especialmente Santiago, la segunda etapa va desde 1990 al 2000, periodo en el cual comienza la producción industrial de la vivienda social y la periferia urbana, la tercera involucra el 
periodo comprendido entre el 2000 y 2005 y es cuando se produce el desborde de la vivienda social, la que sale de los márgenes urbanos, y finalmente la cuarta etapa va desde el 2006 hasta la actualidad y en ella se logra aprender de los errores cometidos y la expulsión de los estratos bajos de la ciudad comienza a disminuir su intensidad.

Finalmente también es importante agregar que los procesos aquí descritos están basados en las dinámicas que se han experimentado esencialmente en las grandes áreas metropolitanas nacionales y en algunas capitales regionales. A continuación revisaremos cada una de estas etapas identificadas.

\section{LA ERRADICACIÓN Y RADICACIÓN DE CAMPAMENTOS: LOS RICOS CON LOS RICOS, LOS POBRES CON LOS POBRES (1979-1989)}

El primer periodo está marcado transversalmente por dos programas de vivienda social impulsados por el MINVU, el de erradicación y radicación de los campamentos. Estos programas involucraron el traslado de algunos asentamientos irregulares (erradicación), o la consolidación de la localización de otros algunos espacios del medio urbano (radicación). La dinámica y movilidad intra-urbana generada por estos dos programas termina, como veremos, por acrecentar la segregación espacial y social de las ciudades nacionales, trasladando la polarización política de la época también al espacio urbano.

En 1979 el MINVU encarga a los secretarios regionales ministeriales (SEREMI) de vivienda realizar un catastro de los campamentos existentes en Chile a ese año, con el objetivo de cuantificar las personas y viviendas que habitaban en ellos. Las décadas anteriores dejaron un total de 51.797 familias y algo así como 259.000 personas que habitaban en los 390 campamentos que había solamente en la ciudad de Santiago. Estos asentamientos irregulares fueron generados en los años anteriores principalmente a partir de la llamada operación sitio y las constantes tomas de terrenos.

Con la información entregada por el catastro se determinó, desde el MINVU, que era necesario erradicar algunos campamentos y otros dejarlos localizados en el mismo lugar en que se encontraban. Los criterios establecidos para determinar si el asentamiento debía ser erradicado o no ser erradicado eran tres, primero si se localizaba en un sector con alto potencial de inversión (Donoso y Sabatini, 1980), segundo el valor del suelo para ese año y tercero la vulnerabilidad geográfica que presentaba el lugar (Hidalgo, 2005).

Tomada la decisión este programa comenzó a desmantelar las viviendas existentes en campamentos y otros asentamientos irregulares, teniendo el programa de erradicación su punto álgido entre 1979 y 1984, periodo en que se trasladaron cerca de 78.820 familias, aproximadamente 400.000 personas (Hidalgo, 2005). Cabe destacar la poca resistencia a los programas de erradicación de campamentos debido a las medidas represivas con las que contaba el estado en pleno periodo de dictadura.

Ahora bien, ¿dónde se localizó la población que estaba siendo erradicada? con el fin de restituir los terrenos ocupados ilegalmente a los propietarios originales y liberarlos así para la acción privada, los campamentos y asentamientos irregulares fueron erradicados y su población localizada en la periferia urbana, en lugares aislados del resto de la ciudad (Fadda y Ducci, 1993), espacios que no contaban con la infraestructura y 
equipamiento necesario para recibir los grandes contingentes de población que estaban llegando (Hidalgo, 1999).

Los terrenos y comunas que recibieron a esta población, preferentemente las del norponiente y sur de Santiago, no estaban, como señalamos, preparadas en términos de los servicios y equipamiento necesarios para recibir a esta nueva población. A esta situación se le agregó que "en la mayoría de los casos los propios departamentos técnicos de los municipios receptores no tuvieron participación en la decisión de ubicar nuevos contingentes en sus respectivos territorios" (Hidalgo, 2004, p. 228) lo que limitó las acciones que podían realizar estos para recibir a la población erradicada.

Las consecuencias espaciales generadas por el programa de erradicación fueron en primer lugar un excesivo crecimiento horizontal de la ciudad, en el caso de la ciudad de Santiago esta creció a un ritmo de 1.200 hectáreas por año entre 1979 y 1984, este crecimiento horizontal generó a la vez la urbanización de suelos que antes eran dedicados a la agricultura o a la actividad ganadera, y además se suma a lo anterior la localización de algunos conjuntos sociales en áreas que presentaban importantes niveles de riesgo natural. En segundo lugar el traslado de familias significó el aumento de la densidad y concentración poblacional en zonas con altos índices de pobreza, generando con ello serios problemas de segregación socioespacial y estableciendo procesos que como veremos más adelante, se profundizan en las siguientes décadas por la propia acción de la política de vivienda social. Respecto a este segundo punto E. Morales y S. Rojas (1986) quienes realizan un estudio sobre la relocalización de la pobreza en los ochenta, señalan que el programa de erradicación "ha tendido a homogeneizar internamente los espacios comunales, dando lugar a comunas ricas, descongestionadas de bolsones de pobreza, y, a comunas pobres. Este corte social ha contribuido aún más a acentuar los rasgos heterogéneos de la ciudad, polarizando el espacio urbano" (p. 48).

El programa de radicación complementa al programa anterior, aportando de igual forma al proceso de concentración de los grupos de estrato social bajo en un determinado lugar de la ciudad y contribuyendo con ello a la segregación socioespacial. Con este programa se mantiene la localización de algunos asentamientos irregulares. Los asentamientos que mantienen su localización por lo general eran los que estaban mal ubicados, presentaban un bajo valor de suelo, estaban mal servidos y presentaban un muy bajo potencial para la inversión privada. R. Hidalgo (2005) señala que en el caso de Santiago los municipios que concentraron las obras de radicación son los mismos que concentraron la llegada de nuevos habitantes a partir de las erradicaciones realizadas, al respecto agrega que "los municipios de Peñalolén, La Pintana, San Bernardo, Recoleta, Maipú, La Florida, Renca, El bosque y Cerro Navia concentran cerca del 70\% del total de las obras de radicaciones" (p. 388).

En síntesis, los programas de erradicación y radicación en Santiago "limpiaron" las comunas de estrato socio económico alto como Las Condes, Santiago, Providencia, La Reina, etc. trasladando a los pobres a vivir en comunas mal servidas, sin equipamientos y con altos niveles de pobreza en la periferia de la ciudad. Se les impidió entonces a los pobres crear su propia ciudad, tal como lo estaban haciendo en gran parte de las ciudades de América. (Ducci, 1997). El neoliberalismo comienza a expresar su cara espacial, la de una ciudad altamente polarizada y fragmentada. 
Figura 1. Movilidad de los campamentos en la década del ochenta en Santiago de Chile

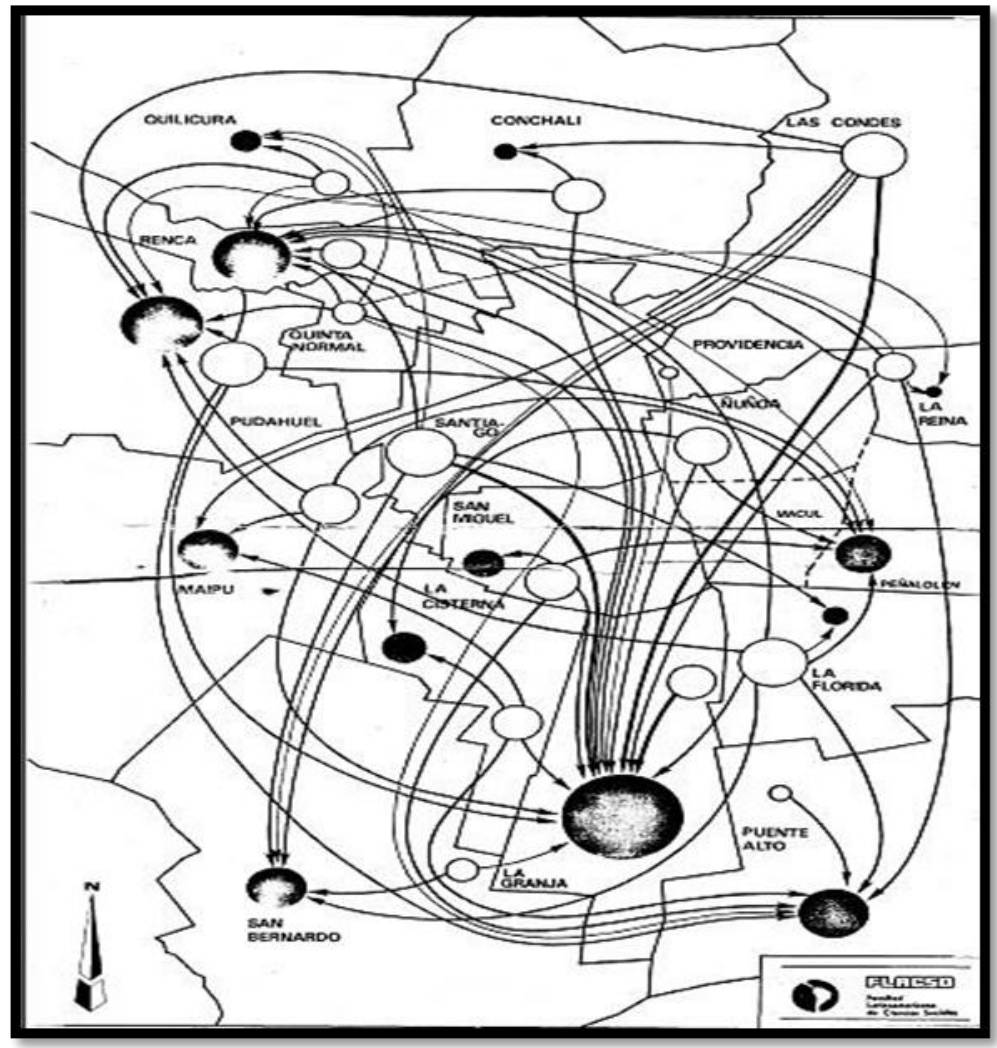

Fuente: E. Morales y S. Rojas (1986).

\section{LA CONSTRUCCIÓN INDUSTRIAL DE LA VIVIENDA SOCIAL Y LA PERIFERIA URBANA: LOS POBRES A LA PERIFERIA (1990-2000)}

R. Hidalgo, H. Zunino y L. Álvarez (2007) señalan que “el decenio de 1990 ha quedado registrado en la historia de las políticas de vivienda como uno de los periodos en que se edificaron el mayor número de viviendas sociales en Chile, y por ende el lapso de tiempo en que se redujo con mayor rapidez el déficit habitacional". La acción impulsada por el estado en la década del ochenta no logró reducir el déficit de vivienda, los datos cuantitativos son tajantes e indican que en 1983 el déficit habitacional era de 841.772 en tanto que hacia 1990 este alcanzaba las 888.681 viviendas $^{2}$, es decir la acción estatal en materia de vivienda no fue capaz de reducir el déficit existente. Esta cifra se redujo hacia el inicio de este siglo a cerca de 450.000 viviendas, lo que significa que en promedio entre 1990 y el 2000 se entregaron anualmente cerca de 80 mil soluciones habitacionales. Esto nos lleva a pensar que en la década del noventa la producción de la vivienda social adquiere ribetes industriales.

Ahora bien, ¿qué parte de la ciudad acogió estas nuevas viviendas y las grandes masas de estrato bajo movilizadas con ellas? Durante esta década los criterios de localización en los ochenta continúan, la vivienda social por tanto se sigue localizando en las áreas

\footnotetext{
${ }^{2}$ El aumento del déficit habitacional según T. Castañeda y J. Quiroz (1986) se explica por el crecimiento que habrían experimentado las familias, ante esta situación el estado no fue capaz de cubrir las crecientes necesidades de vivienda.
} 
donde el precio del suelo es más bajo, esto es en la periferia urbana mal servida, la que de igual forma se produce durante esta década con ribetes industriales.

Un estudio realizado por el MINVU el año 2007 dio cuenta del crecimiento de la superficie urbana experimentada por todas las ciudades de más de 15.000 habitantes entre el año 1993 y 2003. Los resultados de este estudio indican que las ciudades nacionales experimentaron en este periodo un fuerte crecimiento de su superficie urbana, destacan aquí los casos de las siguientes ciudades intermedias menores ${ }^{3}$ : Los Álamos, Frutillar, Quellón, Angol y Curicó, todas ellas con más de un $80 \%$ de aumento de superficie en un lapso de tan sólo 10 años. Por el lado de las ciudades intermedias mayores, casi todas capitales regionales, destacan los casos de la conurbación SerenaCoquimbo, Iquique-Alto Hospicio, Temuco-Padre las Casas y Chillan-Chillán Viejo, todas ciudades que aumentaron su superficie en más de un 50\%. Finalmente, y en términos de porcentaje con niveles menores de crecimiento se ubican las áreas metropolitanas nacionales, al respecto la que experimentó un mayor aumento de su superficie urbana fue Concepción $(48,36 \%)$, le sigue Valparaíso $(25,54 \%)$ y finalmente Santiago $(20,25 \%)$.

Según lo señalado por la literatura especializada el crecimiento de la superficie urbana experimentado durante este periodo por las ciudades nacionales se explica esencialmente debido a la construcción masiva de la vivienda social, la que pasa a transformarse en un símbolo del paisaje urbano de la ciudad Chilena (Hidalgo, 1997, 2007). El estado es entonces durante los noventa el principal constructor del crecimiento horizontal de la ciudad a través de la política de vivienda social.

En los noventa la solución elegida por los distintos gobiernos fue construir la mayor cantidad de soluciones habitacionales posibles, se consideraba entonces que a través de la construcción de grandes conjuntos de vivienda social disminuirían los costos de producción y sería con ello posible aumentar el número de beneficiarios y maximizar las ganancias de las empresas privadas (Hidalgo, 2004) las que en este tiempo se consolidan en la dinámica del sistema de subsidio.

Sin embargo más allá del éxito cuantitativo de la política de vivienda social durante los noventa, comienzan a aparecer algunos problemas. Como revisamos la vivienda social en esta década se continua localizando en la periferia urbana, espacio que presentaba los menores precios de suelo urbano y además donde se ubicaban los principales terrenos disponibles para construcción (Hidalgo, 2004), esto genera inmediatamente un proceso de densificación de la periferia urbana, proceso que se ve potenciado debido a la tipología de construcción preferida de la época: el block de departamento.

La acumulación de la vivienda social en los terrenos mal servidos de la periferia urbana, generó un proceso de profundización de la segregación social y espacial en las ciudades, la literatura especializada establece que durante esta década se comienzan a construir verdaderos guetos de vivienda social (Sabatini, Cáceres y Cerda, 2001), áreas desconectadas del resto de la ciudad, donde sólo habita población de estrato económico bajo, que presentan un rápido deterioro de la infraestructura recreativa, pocas áreas verdes, escasos espacios de participación social y además altos niveles de delincuencia

\footnotetext{
${ }^{3}$ Según el MINVU (2007), se entiende por ciudad intermedia menor aquella cuya población fluctúa entre 20.000 y 99.999 habitantes. La ciudad intermedia mayor tiene una población entre 100.000 y 300.000 habitantes.
} 
(Ducci, 1997; Hidalgo, 2007) tal es el caso por ejemplo del sector "Bajos de Mena" en la Comuna de Puente Alto. Estos guetos urbanos se produjeron por que "los planificadores pensaron las vivienda solo con el fin de resolver con ellas el problema de alojamiento, pero sin considerar la integración social y espacial de estos espacios a la área urbana consolidada" (Hidalgo, 2004).

En los guetos urbanos comienza lentamente a aparecer una verdadera subcultura de la desesperanza, además se evidencia en ellos un fuerte proceso de desintegración social (Sabatini, Cáceres y Cerca, 2001; Hidalgo 2007). Con el paso del tiempo comienza a surgir en estos espacios un nuevo tipo de pobreza urbana (Tironi, 2003), pobreza que la literatura ha denominado de "los con techo" (Rodríguez y Sugranyes, 2004).

\section{Figura 2. Viviendas sociales construidas en el área metropolitana de Santiago, 1991-2000}

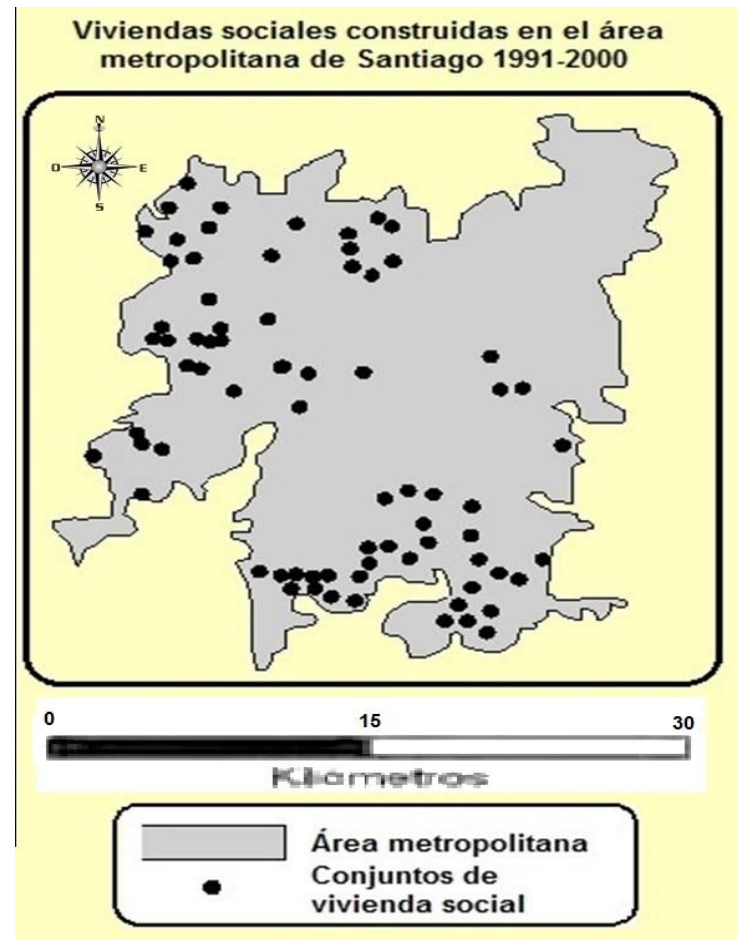

Fuente: Elaboración propia a partir de R. Hidalgo (2007).

En resumen, la construcción industrial de la vivienda social generó un aumento de la superficie urbana de las ciudades nacionales ya que esta se localizó esencialmente en la periferia urbana haciendo que la ciudad creciera de forma horizontal. A la vez la periferia urbana experimentó un proceso de densificación. Producto de la llegada masiva de nuevos habitantes se comienzan a crear grandes áreas sin servicios, sin equipamiento y tan solo con un tipo de clase social; la baja. Se forman así a partir de la acción del estado grandes guetos de pobreza, los que son la máxima expresión de la segregación social y espacial generada por la política de vivienda social que privilegiaba 
la cantidad por sobre la calidad. Los pobres ya están concentrados en el borde de lo urbano.

\section{EL ESPACIO RURAL, NUEVO ESPACIO EN LA CONSTRUCCIÓN DE VIVIENDAS SOCIALES Y EL DESBORDE DEL LÍMITE URBANO: LOS POBRES FUERA DE LA CIUDAD (2000-2005)}

En los primeros cinco años del nuevo milenio se comienza a consolidar una dinámica urbana iniciada a mediados del periodo anterior; la precariopolis estatal.

Como revisamos, en los noventa se había continuado con el patrón de localización de viviendas sociales iniciado décadas atrás, el que estaba determinado por el valor que adquiría el suelo urbano, esto generó que las viviendas sociales se continuaran construyendo en la periferia de las ciudades y por tanto los pobres se continuaran localizando en los límites de la mancha urbana. La gran acumulación de vivienda social y de la pobreza en áreas determinadas, generó grandes guetos urbanos que durante este periodo continúan presentes. Sin embargo y producto de la especulación del mercado inmobiliario sobre los precios del suelo urbano, la ciudad de forma progresiva no pudo sostener más a nuevos conjuntos de vivienda social en áreas periféricas, por lo que la vivienda social se comenzó a construir en los espacios rururbanos alejados de la mancha urbana (Hidalgo et al, 2008) y donde los valores de suelo eran más bajos. Esta búsqueda de espacios más baratos para construir la vivienda social generó espacios mono funcionales, segregados y fragmentados, con calles sin pavimentar, y carentes de todo tipo de servicios, sin áreas de esparcimiento y ubicados fuera del área urbana, esto es lo que R. Hidalgo, H. Zunino y L. Álvarez (2007) y R. Hidalgo et al (2008) denomina precariopolis estatal.

Esta nueva dinámica urbana no es exclusiva a Santiago, a modo de ejemplo también se puede agregar el caso de dos ciudades del sur de Chile; Puerto Montt y Temuco. Desde el decenio anterior estas ciudades experimentaron fuertes crecimientos de población, la primera debido a la actividad acuícola y la segunda debido a la centralización de los servicios y comercio regional, actividades que ofrecieron muchos puestos de trabajo lo que favoreció la migración campo-ciudad y la migración desde otras áreas urbanas locales, regionales y nacionales. Como aumentó la población de estas ciudades, aumentó también la necesidad de vivienda, de manera que se gatilló con ello un proceso de especulación inmobiliaria sobre el precio del suelo urbano, el que se elevó considerablemente durante este periodo. Producto de esta situación el encontrar terrenos cuyo valor sea compatible con los aportes realizados por los subsidios habitacionales en el área urbana se volvió una tarea muy difícil, al respecto A. Bordorf, R. Sánchez y C. Marchant (2008) señalan que "efectivamente, por ejemplo para una vivienda cuyo valor llega a 400 UF, el estado solo tiene capacidad de gastar 65 UF en suelo, lo cual implica que una familia solo podrá habitar en lugares donde el precio del suelo no llegue a valores superiores a 0,4 UF $\mathrm{m} 2$, lo que prácticamente impide la construcción de viviendas sociales en áreas consolidadas de la mayoría de las ciudades Chilenas" (Borsdorf, Sánchez y Marchant, 2008). 
Figura 3. La precariopolis estatal de Alerce, Chile

La precariopolis estatal de Alerce, Región de Los Lagos, Chile

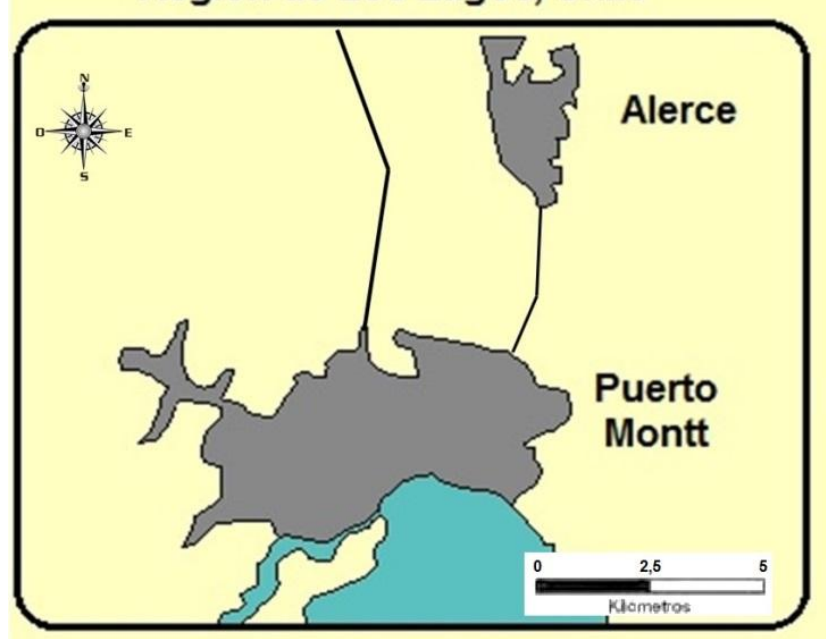

Fuente: Elaboración propia.

La ciudad de puerto Montt comenzó a construir sus viviendas sociales en el sector Alerce, ubicado a $8 \mathrm{Km}$ al norte de Puerto Montt y a $10 \mathrm{~km}$ al sur de Puerto Varas y en el caso de Temuco se comienzan a consolidar las áreas de Cajón, Labranza y Fundo el Carmen. Se produce así en las ciudades chilenas un desborde de la vivienda social de los límites urbanos, construyéndola ahora en los alrededores de la mancha urbana y ya no en el área consolidada (Hidalgo, 2007), los estratos bajos salen a vivir fuera de la ciudad.

Ahora bien, realizando una reflexión en base a lo propuesto por H. Capel (2003), la precariopolis estatal no son nuevas ciudades ya que estos nuevos espacios carecen de algunas características básicas como la variedad de clases sociales, debido a que en ellos se concentra la población de estrato socioeconómico bajo, también carecen de servicios y equipamiento urbano, como agua, luz y alcantarillado e incluso calles pavimentadas (Hidalgo et al, 2008). La precariopolis estatal se constituye entonces como espacios dormitorios ya que no ofrecen al habitante fuentes laborales estables y masivas, las personas deben realizar movimientos pendulares día a día con el fin de trasladarse a trabajar o bien a estudiar a la ciudad más cercana de la cual además son dependientes. Al igual que la periferia urbana la precariopolis estatal es un área mal servida y con costos de traslado a la ciudad, en términos económicos y temporales, aún mayores que en los grandes guetos creados en los noventa. Son entonces espacios sometidos y dependientes de la ciudad consolidada.

\section{¿APRENDIENDO DE LOS ERRORES? (2006-2012)}

La acción del estado subsidiario a través de la política de vivienda social y la política de desarrollo urbano, sobre las ciudades nacionales ha construido, según lo revisado hasta 
el momento, ciudades altamente fragmentadas, polarizadas y segregadas, con las clases bajas habitando la periferia urbana y la precariopolis estatal, es decir fuera de los límites de la ciudad. Además se ha contribuido a que los límites de las grandes áreas urbanas (metropolitanas e intermedias mayores) sean cada vez más difusos. Ahora bien, ¿qué ha pasado desde el 2006 hasta hoy?

Hay pocas investigaciones que den cuenta de los impactos de la nueva política de vivienda social sobre las ciudades nacionales en el periodo 2006-2013 y que den luces de la movilidad espacial de los pobres en la ciudad. Sin embargo destacan los aportes realizados por el sociólogo Francisco Sabatini, quien ha intentado generar un modelo que permitan construir ciudades más inclusivas en concordancia con el nuevo enfoque que posee la política de vivienda social.

Hacia el 2006 la política de vivienda social comienza a experimentar algunos cambios profundos, si bien es cierto los objetivos de disminuir el déficit habitacional y mejorar la calidad de la vivienda continuaban, se agregaba uno nuevo, el de generar ciudades con mayores niveles de integración social, aprendiendo así de algunos de los errores cometidos por esta política estatal en el pasado. Esto implicaba frenar la expulsión de los pobres de la ciudad con el fin de comenzar a integrarlos dentro del área urbana consolidada donde puedan convivir con otros grupos sociales y aumentar la heterogeneidad social en todo el espacio urbano.

La acción del estado y del mercado a través de la política de vivienda social desde el 2006 ha gatillado dos procesos paralelos en las ciudades chilenas, el primer de ellos es de carácter espontáneo y ha sido originado esencialmente por la acción del mercado y promovido por las inmobiliarias y constructoras, este proceso es la "colonización" de las áreas tradicionalmente de estratos bajos, la periferia urbana y del radio rururbano, por parte de estratos sociales medio o altos, los que ha generado un proceso de gentrificación (Sabatini, Sarella y Vásquez, 2009) de algunos sectores de las ciudades aumentando así el contacto social y espacial entre los estratos bajos, medios y altos. Esta situación ha contribuido a disminuir los niveles de segregación en las ciudades convirtiendo áreas que antes eran homogéneas en áreas con mayores niveles de diversidad socioeconómica e integradas con servicios y equipamientos a la ciudad consolidada. La razón de este proceso está en la movilidad interna de los estratos medios y altos hacia sectores periféricos a través de la tipología de parcelas de agrado o bien barrios inmobiliarios destinados a ese segmento de la población nacional.

El segundo proceso ha sido generado esencialmente desde el estado el que ha buscado a través de diversos programas habitacionales desarrollados en los últimos dos gobiernos, incluir a las personas de estrato bajo en sectores tradicionalmente de estratos medios y altos, "al buscar incluir familias de bajos ingresos en zonas de medios o altos ingresos, lo que se intenta es reducir la aglomeración de viviendas sociales, entendiendo que es mejor que ellas estén emplazadas en barrios no populares" (Sabatini et al, 2010, p. 251) se apuesta así por la dispersión espacial de la vivienda social. Por lo tanto la movilidad de los estratos bajos hoy, aunque aún con ciertas falencias, no solo está dirigida en su totalidad hacia la periferia urbana ni tampoco hacia la precariopolis estatal, sino que también hacia lugares de la ciudad ya consolidados.

¿Y qué ha sucedido con la precariopolis estatal creada en el periodo anterior?, estas áreas han expandido su superficie y han aumentado el número de viviendas en ellas, tal es el caso de Alerce y los casos revisados en Temuco. Ahora bien, este proceso ha ido 
acompañado de la llegada de servicios municipales e infraestructura urbana a estas áreas, además de nuevos vecinos de estrato social medio quienes también, en estos últimos años, han logrado acceder de forma plena al subsidio del estado.

En resumen, al parecer se está aprendiendo de los errores cometidos, se están generando ciudades más integradas socialmente, esto gracias a una acción más amplia del estado y a algunas dinámicas propias del mercado inmobiliario. Tal como señaló Bachelet en 2006 se quiere dejar de construir dos ciudades en una, ahora es necesario generar medidas correctivas que permitan unir socialmente aquella ciudad quebrada por una política de vivienda centrada en la cantidad y al parecer muy poco en la calidad.

\section{REFLEXIONES FINALES}

Durante cuatro décadas la movilidad de la pobreza estuvo dirigida hacia los límites de la ciudad o bien hacia el exterior de esta. La política de vivienda social y la de desarrollo urbano, que se han regido esencialmente desde la década del setenta por las leyes del mercado y que han sido diseñadas desde el estado ya reestructurado, han tendido a expulsar a los estratos bajos de los lugares mejor ubicados de la ciudad en los ochenta, excluirlos a la periferia urbana en los noventa y expulsarlos fuera de los límites de la ciudad consolidada en el nuevo milenio, resguardando así los buenos lugares de la ciudad exclusivamente a los estratos socioeconómicos altos. Ahora bien, tal como señala R. Hidalgo (2007), el suelo de la gran ciudad se está acabando, lo que ha gatillado entre otros fenómenos una nueva localización de las clases medias y altas en la periferia urbana, donde antes se ubicaban preferentemente los conjuntos de vivienda social y los estratos bajos, abriendo procesos de gentrificación en amplios sectores casi marginales de la mancha urbana, con ello ha disminuido la segregación espacial ya que las áreas se han vuelto más heterogéneas en términos de clases sociales.

La razón de fondo de la localización de la vivienda social y por tanto de la movilidad de los pobres en la ciudad es el progresivo aumento de precio del suelo urbano, el que experimentó un alza de un 800\% en el caso de la ciudad de Santiago entre 1990 y 2000. Tal como señalan I. Brain y F. Sabatini (2006), el aumento del precio del suelo comienza lentamente a carcomer los aumentos experimentados por los subsidios habitacionales, de manera que necesariamente y obligados por la propia dinámica del mercado de suelo, los pobres deben salir de la ciudad en búsqueda de terrenos más baratos. Al respecto, D. Harvey (1977) plantea que la ciudad es una reproducción de los intereses económicos de clase y de políticos quienes despliegan sobre la ciudad relaciones y estrategias de poder con el fin de construir esta según sus propios intereses (Zunino, 2002). Analizando desde esta perspectiva teórica la política de desarrollo urbano, que ha dejado el crecimiento de las ciudades al libre juego de las fuerzas del mercado y ha promovido la ausencia del estado en la planificación urbana, es posible señalar que esta ha generado de manera paulatina fuerzas centrífugas que han expulsado a los pobres de la ciudad y los han trasladado a áreas rurales consolidando así por un lado a los procesos de segregación social y espacial, pero además contribuyendo a la construcción de una ciudad difusa y fragmentada, sin límites claros gracias a la formación de algunas celular urbanas alrededor de la ciudad consolidada como lo es la "precariopolis" estatal. 
Estas fuerzas centrífugas que han sido provocadas por los principios que rigen actualmente la política de desarrollo urbano, se han canalizado a través de la política de vivienda social, política que se ha convertido en el mecanismo que ha alejado a los pobres de los buenos lugares de la ciudad. Así es finalmente el estado subsidiario quien termina, con o sin intensión, expulsando a los pobres de la ciudad y resguardando los mejores lugares de esta solo a quienes puedan pagar por ellos.

Las investigaciones referidas a la localización de la vivienda social y a la movilidad de los estratos bajos en las últimas décadas en las ciudades chilenas se han centrado principalmente en las grandes áreas metropolitanas, y es que en estas los efectos de esta política han sido más evidentes. En menor medida se han estudiado estos temas en las ciudades intermedias mayores, las que continúan las tendencias experimentadas por las grandes áreas metropolitanas, aunque la escala de los efectos es menor. Sin embargo existen muy pocos estudios que intenten conocer los impactos de la vivienda social y la movilidad de los pobres en las ciudades menores, estas ciudades han sido prácticamente inexploradas desde este punto de vista. Ante esta situación surgen distintas preguntas respecto a las ciudades intermedias menores, a saber: ¿cómo han respondido estas ciudades a las políticas de vivienda social?, ¿los conjuntos de vivienda social construidos han generado mayores niveles de segregación social y espacial o los han disminuido?, ¿los conjuntos se localizan en la periferia, en las áreas rururbanas o en la ciudad consolidada?, ¿se han replicado en ellas los efectos negativos de la política de vivienda social y de desarrollo urbano ya documentadas en las grandes ciudades?, entre muchas otras. Así, esta área de estudio se puede comenzar a constituir como una veta para futuras investigaciones con el objetivo de conocer si estas ciudades han continuado las trayectorias de las demás o han seguido alguna trayectoria distinta con particularidades propias de cada ciudad.

\section{BIBLIOGRAFÍA}

AZOCAR, G., HENRÍQUEZ, C., VALENZUELA, C. y ROMERO, H. Tendencias sociodemográficas y segregación socioespacial en Los Ángeles, Chile. Revista de Geografía Norte Grande, 2008, n 41, p. 103-128.

BORSDORF, A., SÁNCHEZ, R. y MARCHANT, C. Aprendiendo de los errores. La necesidad de cambios a la política nacional de vivienda en ciudades intermedias Chilenas. Coloquio Internacional de Geocrítica, 2008, $\mathrm{n}^{\circ}$ 10, Barcelona. Disponible en: <http://www.ub.edu/geocrit/sn/sn-270/sn-270-51.htm>. [Consultado: Diciembre/2012].

BRAIN, I. y SABATINI, F. Los precios del suelo en alza carcomen el subsidio habitacional, Contribuyendo al deterioro en la calidad y localización de la vivienda social. Prourbana, 2006, $n^{\circ}$ 4. p. 2-13.

CAPEL SÁEZ, H. A modo de introducción. Los problemas de las ciudades: urbs, civitas y polis. In: Capel, H. (Coord.). Ciudades, arquitectura y espacio urbano. Almería: Instituto de Estudios de Cajamar, 2003, p. 9-22.

CASGRAIN, A. La apuesta del endeudamiento en la política habitacional Chilena. Revista INVI, 2010, vol. 25, $\mathrm{n}^{\circ}$ 68, p. 155-182. 
CASTAÑEDA, T. y QUIROZ, J. Las políticas de vivienda en Chile y su impacto redistributivo en 1969, y 1980-1983. Estudios Públicos, 1986, vol. 22, p. 1-50.

CASTILlO, M. y HIDALGO, R. 1906/2006 cien años de políticas de vivienda en Chile. Santiago de Chile: Geolibros, 2005.

CHONCHOL, J. Reflexiones sobre Chile: ¿hay alternativa al modelo neoliberal? Estudios Avanzados, 1996, vol. 10, n 27, p. 141-162.

DE MATTOS, C. Modernización neocapitalista y reestructuración productiva y territorial en Chile, 1973-90. EURE, 1992, vol. 18, n 54, p. 15-30.

DONOSO, F. y SABATINI, F. Santiago: empresa inmobiliaria compra terrenos. EURE, 1980, vol. $7, \mathrm{n}^{\circ} 20$. p. 25-51.

DUCCI, M. Chile: el lado obscuro de una política de vivienda exitosa. EURE, 1997, vol. 23, n 69. p. 99-115.

FADDA, G. y DUCCI, M. Políticas de desarrollo urbano y vivienda en Chile: Interrelaciones y efectos. In: Bravo, L. y Martínez, C. (Coords.). Chile: 50 años de vivienda social, 1943-1993. Valparaíso: Universidad de Valparaíso, 1993, p. 77-112

FRIEDMANN, J. The World City Hypothesis. Development and Change, 1986, vol. $17, \mathrm{n}^{\circ} 1$, p. 69-84.

GARÍN, A., SALVO, S. y BRAVO, G. Segregación residencial y políticas de vivienda en Temuco. 1992-2002. Revista de Geografía Norte Grande, 2009, n 44, p. 113-128.

GARRETÓN, M. Modelo y proyecto político del régimen militar Chileno. Revista Mexicana de Sociología, 1982, vol. 44, n 2, p. 355-372.

HARAMOTO, E. Vivienda social. Tipología de desarrollo progresivo. Santiago de Chile: INVI y Centros de Estudio de la Vivienda Universidad Central, 1987.

HARVEY, D. Urbanismo y desigualdad social. Madrid: Siglo Veintiuno, 1977.

HARVEY, D. La condición de la posmodernidad, investigación sobre los orígenes del cambio cultural. Buenos Aires: Amorrortu Editores, 1998.

HIDALGO, R. La vivienda social en la ciudad de Santiago: Análisis de sus alcances territoriales en la perspectiva del desarrollo urbano, 1978-1995. Revista de Geografía Norte Grande, 1997, $\mathrm{n}^{\circ} 24$, p. 31-38.

HIDALGO, R. La vivienda social en Chile: la acción del estado en un siglo de planes y programas. Coloquio Internacional de Geocrítica. 1999, $\mathrm{N}^{\circ} 45, \mathrm{~N}^{\circ} 1$. Disponible en: <http://www.ub.edu/geocrit/sn-45-1.htm>. [Consultado: Marzo/2013].

HIDALGO, R. La vivienda social en Santiago de Chile en la segunda mitad del siglo XX: Actores relevantes y tendencias espaciales. In: De Mattos, C., Ducci, M., Rodríguez, A. y Sugranyes, A. (Coords.). Santiago en la globalización: ¿Una nueva ciudad. Santiago de Chile: Ediciones Sur-Libros Eure, 2004, p. 219-242. 
HIDALGO, R. La vivienda social en Chile y la construcción del espacio urbano en el Santiago del siglo XX. Santiago de Chile: Serie Geolibros, 2005.

HIDALGO, R. ¿Se acabó el suelo en la gran ciudad? Las nuevas periferias metropolitanas de la vivienda social en Santiago de Chile. EURE, 2007, vol. 33, n 98 , p. 57-75.

HIDALGO, R., BORSDORF, A., ZUNINO, H. y ÁlVAREZ, L. Tipologías de expansión metropolitana en Santiago de Chile: Precariópolis estatal y Privatópolis inmobiliaria. Scripta Nova, 2008, Vol. 12, $\mathrm{n}^{\circ}$ 270. Disponible en: <http://www.ub.edu/geocrit/sn/sn-270/sn-270-113.htm>.[Consultado: Diciembre/2012].

HIDALGO, R., ZUNINO, H. y ÁLVAREZ, L. El emplazamiento periférico de la vivienda social en el área metropolitano de Santiago de Chile: Consecuencias socioespaciales y sugerencias para modificar los criterios actuales de localización. Scripta Nova, 2007, Vol. 11, n 245. Disponible en: <http://www.ub.edu/geocrit/sn/sn24527.htm>. [Consultado: Diciembre/2012].

HUERTA, M. El neoliberalismo y la conformación del estado subsidiario. Política y Cultura, 2005, $\mathrm{n}^{\circ}$ 24, p. 121-150.

Instituto Nacional de Estadística. Compendio estadístico año 2012, Chile. 2012. Disponible en: <http://www.ine.cl/canales/menu/publicaciones/compendio_estadistico/compendio_esta distico2012.php>. [Consultado: Julio/2013].

Ministerio de Vivienda y Urbanismo. Memoria 1975, Santiago de Chile: Ministerio de Vivienda y Urbanismo, 1976.

Ministerio de Vivienda y Urbanismo. Medición de la superficie ocupada por las ciudades de Chile de más de 15.000 Habitantes: 1993-2003. Santiago de Chile: Ministerio de Vivienda y Urbanismo, 2007.

MONTES, C. A 20 años de la liberalización de los mercados de suelo. Revista urbanismo, $1999 . \quad$ Disponible en: <http://www.scielo.cl/scielo.php?script=sci_arttext\&pid=S0250-71612000007700006 $>$. [Consultado: Diciembre/2012].

MORALES, E. y ROJAS, S. Relocalización socio-espacial de la pobreza. Política estatal y presión popular, 1979-1985. Documento de Trabajo Programa FLACSO. Santiago de Chile, 1986, $\mathrm{n}^{\circ} 280$.

PALMA, E. y SANFUENTES, A. Políticas estatales en condiciones de movilización social: las políticas de vivienda en Chile. EURE, 1979, Vol. 6, n 16, p. 23-55.

RODRÍGUEZ, A. y SUGRANYES, A. El problema de vivienda de "los con techo". EURE, 2004, vol. 30, n 91, p. 53-65.

SABATINI, F. Reforma de los mercados de suelo en Santiago, Chile: efectos sobre los precios de la tierra y la segregación residencial. EURE, 2000, vol. 26, n 77, p. 49-80. 
SABATINI, F., CÁCERES, G. y CERDA, J. Segregación residencial en las principales ciudades chilenas: Tendencias de las tres últimas décadas y posibles cursos de acción. EURE, 2001, vol. 27, $\mathrm{n}^{\circ} 82$, p. 21-42.

SABATINI, F., EDWARDS, G., CUBILLOS, G., BRAIN, I., MORA, P. y RASSE, A. Dispersión espacial de vivienda económica como vía de integración social urbana. In: Centro de Políticas públicas Universidad Católica de Chile. Camino al Bicentenario, propuestas para Chile. Santiago de Chile, 2010, p. 247-274.

SABATINI, F., SARELLA, M. y VÁSQUEZ, H. Gentrificación sin expulsión, o la ciudad latinoamericana en una encrucijada histórica. Revista 180 Arquitectura, Arte y Diseño, 2009, vol. 24. p. 18-25.

SASSEN, S. The Global City: New York, London, Tokyo. New Jersey: Princeton University Press, 1991.

SUGRANYES, A. Las política habitacional en Chile, 1980-2000: un éxito liberal para dar techo a los pobres. In: Rodríguez, A. y Sugranyes, A. (Coords.). Los con techo, un desafio para la política de vivienda social. Santiago de Chile: Ediciones Sur, 2005, p. 23-58.

TIRONI, M. Nueva Pobreza Urbana. Vivienda y capital social en Santiago de Chile, 1985 -2001. Santiago de Chile: PREDES y Editorial RIL, 2003.

VARGAS, O. Neoliberalismo: Principios generales. Temas Sociales, 2000, $\mathrm{n}^{\circ} 21$. Disponible en: <http://www.revistasbolivianas.org.bo/scielo.php?pid=S123443212000000100001\&script=sci_arttext>. [Consultado: Julio/2013].

ZUNINO, H. Formación institucional y poder: investigando la construcción social de la ciudad. EURE, 2002, vol. 28, n 84. p. 103-116.

(C) Copyright Luis Alejandro Vergara Erices, 2014.

(C) Copyright GeoGraphos, 2014.

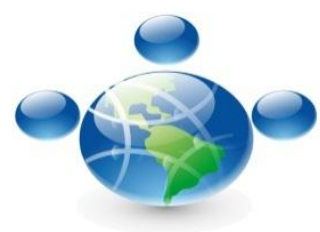

